\title{
Beneficial Effects of Humidified, Warmed Carbon Dioxide Insufflation During Laparoscopic Bariatric Surgery: A Randomized Clinical Trial. What if Sample Size Calculation Made Difference?
}

\author{
L. La Colla $\cdot$ A. Mangano $\cdot$ A. Albertin \\ Received: 19 January 2009 / Accepted: 23 February 2009 / Published online: 10 March 2009 \\ (C) Springer Science + Business Media, LLC 2009
}

Sir:

We read with interest the article published by Dr. Savel and colleagues [1].

While the authors are to be commended for their aim to conduct a prospective, randomized double-blind trial about the effect of warm and humidified carbon dioxide insufflation on postoperative pain and morphine requirements, there seems to be some issues with the study design.

In particular, even though this trial appears to be adequately designed and analyzed, it does not seem to be adequately powered. In fact, in order for a particular finding to be claimed as significant (or not), the study should be adequately powered. The authors state their primary endpoints were visual analogic pain scores (VAS) and morphine requirements. They refer to an older article [2] but, unfortunately, seem to have failed sample size calculation. Nowhere in this reference article is the variability (SD) in morphine requirement at $24 \mathrm{~h} 10 \mathrm{mg}$. Considering a more reasonable variability (SD) of $30 \mathrm{mg}$ and considering a clinically significant difference of $10 \mathrm{mg}$, a total of 193 patients per

Support was provided solely from institutional and/or departmental sources.

\section{La Colla $(\bowtie)$}

Department of Anesthesiology, Vita-Salute San Raffaele

University School of Medicine-IRCCS San Raffaele,

Via Olgettina 60,

Milan 20132, Italy

e-mail: 1.lacolla@studenti.hsr.it

\section{A. Mangano}

Vita-Salute San Raffaele University School of Medicine-IRCCS

San Raffaele,

Milan, Italy

\section{A. Albertin}

Department of Anesthesiology, IRCCS Multimedica,

Sesto San Giovanni,

Milan, Italy group would have been required (considering the "standard" $\alpha$ error of 0.05 and a power of 0.8 ) in this study.

As for VAS, the authors did not perform any sample size calculation, and therefore, it is almost impossible to perform a pre-study sample size calculation. However, assuming a mean VAS value of $2.5 \pm 1.8$ at $24 \mathrm{~h}$ [3] and considering a reduction of 1.8 clinically significant, more than 30 patients per group would have been required. It is also possible to perform a post hoc sample size calculation or power analysis on the statistical tests they have used from their data. In particular, considering a mean VAS value of $3.8 \pm 1.7$ in the control group (Table 2), and a difference of 1.3 , their test had a power of only 0.52 to detect such difference (considering an $\alpha$ error of 0.05 ).

Appropriate sample size calculation and power is mandatory to draw adequate conclusions. In this case, the authors state no differences in opioid requirements and postoperative pain exists between the 2 groups. Are we sure it is really so?

We hope our observations are useful to other authors planning surgical trials.

"Editor's Note: "Dr. Savel was invited to respond to this Letter-to-the Editor and declined."

Conflict of Interest The authors do not have any conflict or financial interest with regard to the issue discussed in this paper.

\section{References}

1. Savel RH, Balasubramanya S, Lasheen S, et al. Beneficial effects of humidified, warmed carbon dioxide insufflation during laparoscopic bariatric surgery: a randomized clinical trial. Obes Surg. 2005;15:64-9.

2. Farley DR, Greenlee SM, Larson DR, et al. Double-blind, prospective, randomized study of warmed, humidified carbon dioxide insufflation vs standard carbon dioxide for patients undergoing laparoscopic cholecystectomy. Arch Surg. 2004;139:739-43; discussion 43-4.

3. Ott DE, Reich H, Love B, et al. Reduction of laparoscopic-induced hypothermia, postoperative pain and recovery room length of stay by pre-conditioning gas with the Insuflow device: a prospective randomized controlled multi-center study. JSLS. 1998;2:321-9. 